\title{
Un acercamiento a la visión del amor en la poesía de Carlos López Degregori: el caso de "Asunta" de Cielo forzado
}

\section{AN APPROACH TO THE IMAGE OF LOVE IN THE POETRY OF CARLOS LÓPEZ DEGREGORI: THE CASE OF "ASUNTA" FROM CIELO FORZADO}

Selenco Vega Jácome

Universidad de Lima

svega@ulima.edu.pe

\section{RESUMEN}

En la poesía de López Degregori (Lima, 1952) encontramos una visión muy particular del amor. No es un simple sentimiento idealizado; por el contrario, en sus versos, el amor es un sentimiento contradictorio que desemboca siempre en un escepticismo radical frente al significado de la existencia. Esta imagen del amor se ejemplifica bastante bien en "Asunta", uno de los textos más representativos de Cielo forzado (1988).

PALABRAS CLAVE: poesía, hablante lírico, amor, existencia

\section{ABSTRACT}

In the poetry of López Degregori (Lima, 1952), we find a very particular vision of love. It is not a simply idealized feeling; in his verses, love is a contradictory feeling that always leads to a radical skepticism of the meaning of human existence. This image of love is exemplified quite well in "Asunta", one of the most representative texts of Cielo forzado (1988).

KEYWORDS: poetry, lyric speaker, love, human existence 
Convertido en uno de los poetas vivos más importantes del Perú, Carlos López Degregori (Lima, 1952) es autor de una obra vasta y compacta, conformada por más de una decena de poemarios recogidos en el volumen Lejos de todas partes (2018). Sus versos, alejados de la impronta coloquial y vitalista tan frecuente en sus compañeros de ruta de los años setenta, poseen una dimensión trágica (O'Hara, 1994) y resaltan por su escepticismo y su falta de humor. Según uno de sus críticos, Fermín Cebrecos (1995), de poemario en poemario se construye un yo poético que rehúye lo anecdótico y lo autobiográfico y, de este modo, logra universalizar la experiencia humana para convertirse en una voz que, finalmente, representa a todos los hombres.

Dentro de esta "universalización de la experiencia humana", en la obra de López Degregori se plasma de manera muy original el tema del amor. No se trata de un mero sentimiento idealizado que nos redime de nuestra condición mortal; por el contrario, en sus versos, el amor es un sentimiento contradictorio del que nadie puede prescindir (Urco, 1994), pero que, lejos de ser ideal o ennoblecedor, desemboca siempre en un escepticismo radical frente al significado de la existencia.

Precisamente, el propósito del presente estudio es realizar un acercamiento inicial a la visión del amor en la obra de Carlos López Degregori. Para ello, nos concentraremos en analizar el poema "Asunta", uno de los más emblemáticos de su cuarto libro, Cielo forzado (1988).

\section{ANÁLISIS DEL POEMA “ASUNTA” DE CIELO FORZADO}

Comencemos citando el poema en su totalidad:

Te traigo, Asunta, estas flores sin nombre del mercado. Son apenas un acto de resistencia, una prueba irrisoria de amor.

Vengo de otra región, Asunta. Apenas logro caminar y tengo la mueca del que no quiso volver, pero no le quedó alternativa. Por eso, cuando me presintieron en el tumulto, todos huyeron despavoridos.

Huélelas con pasión.

Aprisiónalas entre tus dedos como una historia de amor torrencial.

Písalas - Devóralas - Humíllalas.

No importa. Ellas perdurarán mañana cuando no contestes a los golpes densos, helados, insistentes de los vecinos. (López Degregori, 2018, p. 133)

\section{Explicación de nuestro modelo de análisis}

Para nuestro estudio sobre "Asunta", nos detendremos en el análisis formal de sus versos, así como en su estructura y los recursos retóricos empleados, ya que ellos son 
los responsables de la producción de sentidos en el lector. Al respecto, nos apoyaremos en la retórica general textual desarrollada, entre otros, por Arduini (2000), cuyo mérito principal radica en haber recuperado las ideas aristotélicas según las cuales inventio, dispositio y elocutio no existen separadas, sino que deben ser consideradas como una totalidad indivisible. En Prolegómenos a una teoría general de las figuras (2000), el lingüista italiano propone una retórica que considera el análisis de los contextos culturales y de las figuras retóricas, íntimamente ligados con formas cognitivas de captación del mundo. Esta propuesta articula adecuadamente el plano de la elocutio (figuras retóricas) con el de la dispositio (estructura del poema) y la inventio (ideología o cosmovisión).

En consonancia con estas ideas, postulamos un modelo teórico que se apoya en las propuestas de Arduini (2000). No nos interesa realizar un mero y estéril recuento de figuras literarias, sino que proponemos articular el plano de la elocutio (figuras retóricas) al de la dispositio (estructura del poema) y al de la inventio (cosmovisión o universo representado), para abordar así la naturaleza del amor en los versos de "Asunta", de López Degregori.

Además, y ya que ningún texto lírico se produce al margen del proceso de enunciación de sus versos (Friedrich, 1974), incluimos el análisis del plano de los interlocutores. Al respecto, en "Asunta" el hablante lírico se dirige directamente al tú, al ser amado, en un acto de confesión y pretendida intimidad (esto lo demostraremos más adelante). Dentro del circuito comunicativo de cualquier poema existen dos interlocutores básicos: el locutor y el alocutario. El locutor es el emisor del texto: el que cuenta vivencias, describe paisajes o relata historias y que, en el caso del poema, se puede equiparar con el narrador. Este locutor puede ser de dos tipos: locutor personaje o locutor no personaje (Fernández Cozman, 2008). El primero habla en primera persona (yo o nosotros) y participa en mayor o menor medida de los hechos del poema; a este locutor también se le llama yo poético. Por otra parte, el locutor no personaje solo participa como voz transmisora de los textos, sin deícticos como yo o nosotros que podrían delatar su presencia en el aquí y ahora del poema. El locutor se dirige a un alocutario, que también puede ser de dos tipos: el primero, el alocutario representado, se manifiesta en el texto a partir de deícticos clave como tú o usted. En cambio, el alocutario no representado no se manifiesta nunca como una presencia activa en el poema: es como si el locutor hablara consigo mismo, como si a través de un monólogo interiorizado fuera él su propio destinatario.

\section{Análisis de "Asunta"}

\section{Segmentación textual}

Desde el punto de vista de la dispositio, podemos dividir este poema en prosa en tres momentos, de acuerdo con su propia estructura. 
El primer segmento abarca los dos párrafos iniciales. Trata de la presencia del yo poético ante Asunta. Allí se explica la razón de su llegada y los sacrificios que debió hacer para acceder a ella ("Vengo de otra región, Asunta. Apenas logro caminar y tengo la mueca del que no quiso volver, pero no le quedó alternativa...").

El segundo segmento abarca las tres oraciones (o versos) siguientes. Por las marcas textuales de tono apelativo, trata de una serie de órdenes disfrazadas de indicaciones acerca de lo que Asunta debe hacer con la ofrenda del yo poético (es decir, con las flores traídas para ella).

Por último, el tercer segmento del poema comprende el pequeño párrafo final formado por dos oraciones. Allí se anticipa un desenlace trágico para la historia de amor entre el yo poético y su interlocutora. Específicamente, trata de lo que ocurrirá a la mañana siguiente, cuando Asunta sea incapaz de responder a los llamados "insistentes de los vecinos".

\section{Figuras literarias}

En el caso del análisis de las figuras literarias, es necesario recordar que Arduini (2000) propone dos conceptos fundamentales: campo retórico y campo figurativo. El campo retórico es entendido como

la vasta área de conocimientos y las experiencias comunicativas adquiridas por el individuo, por la sociedad y por las culturas. Es el depósito de las funciones y de los medios comunicativos formales de una cultura y, en cuanto tal, es el substrato necesario de toda comunicación. (p. 47)

Todo campo retórico incluye tanto el contexto cultural (la escuela artística dentro del cual surge determinada obra, por ejemplo) como el proceso de recepción del texto literario. Hay campos retóricos amplios como la poesía peruana del siglo xx y otros menos vastos como la poesía peruana de los setenta, dentro de la cual se ubica la obra de López Degregori. Por otra parte, el campo figurativo, según Arduini (2000), es un espacio cognitivo que permite a los poetas organizar el mundo desde una determinada óptica conceptual. De acuerdo con esto, toda figura retórica es mucho más que un adorno estético, ya que posee una dimensión pragmática y cognoscitiva. Podemos hallar seis campos figurativos (estructuras profundas): (1) la metáfora, que incluye la prosopopeya o personificación, el símil, la metáfora misma, etcétera; (2) la metonimia (del tipo causaefecto, autor-obra, abstracto-concreto, etcétera); (3) la sinécdoque, que incluye figuras cuya relación es de inclusión (de parte-todo, todo-parte, etcétera); (4) la elipsis, dentro de la cual se ubica la reticencia, el asíndenton, la elipsis propiamente dicha, etcétera; (5) la antítesis, que incluye el oxímoron, la ironía, el hipérbaton, etcétera; y (6), finalmente, la repetición, dentro de la cual se halla el polisíndenton, la aliteración, la anáfora, etcétera (Vega Jácome, 2015). 
En el poema "Asunta" predominan tres campos figurativos: la elipsis, la repetición y la metáfora. Con respecto a la elipsis, desde el inicio se recurre al empleo del asíndenton, que se materializa en la supresión de los pronombres yo y tú, que hacen referencia a los personajes involucrados en el poema. Así, en la primera línea hay asíndenton cuando el yo poético dice: “Te traigo, Asunta...", en lugar de "Yo te traigo, Asunta...". Sucede lo mismo al principio de la segunda estrofa, pues allí el yo poético afirma: "Vengo de otra región, Asunta...", en vez de "Yo vengo de otra región, Asunta...". Esta recurrencia al asíndenton no es gratuita; por el contrario, la ausencia generalizada de pronombres señala, aunque resulte paradójico, la importancia del o de los personajes involucrados en los versos, en especial el yo (el amante, en este caso). No olvidemos que las normas de construcción sintáctica en el castellano hacen que esperemos la presencia habitual del sujeto de la oración, presencia que se anula constantemente en "Asunta"; ello genera una suerte de "expectativa frustrada" que obliga a los lectores a reparar en los elementos gramaticales faltantes.

Un segundo campo figurativo presente en "Asunta" es la repetición. En los dos primeros párrafos se repite el nombre del interlocutor, es decir, de la amada. Desde el punto de vista semántico, esta recurrencia al nombre de Asunta funciona como una letanía, como un reconocimiento y una invocación casi sagrados a la presencia del sujeto amado. Es sintomático que esta invocación al nombre de Asunta cese de manera abrupta en los versos y párrafos siguientes del poema. El yo sigue dirigiéndose a ella, pero ya no la nombra. Es como si, frente al contacto con ella, y ante el carácter evanescente de su amor, él fuera incapaz de volver a mencionar su nombre.

La metáfora es el tercer campo figurativo predominante en "Asunta". Así, hallamos un tipo de metáfora muy especial: la prosopopeya o personificación. En efecto, las flores que el yo poético ofrece al sujeto amado, Asunta, son como pequeños seres humanos "sin nombre". No solo ello, sino que además se convierten en criaturas dotadas de sentimientos, criaturas sobre las cuales se puede actuar: "Písalas - Devóralas - Humíllalas". Esta visión de las flores como seres humanos degradados resulta de una singularidad ejemplar. En la poesía tradicional, las flores suelen ser consideradas ofrendas dotadas de vida, de luz y de fragancia. Sus valores son altamente positivos. En el poema "Asunta", gracias al empleo de la personificación, esta representación de las flores muda de signo. Las flores se convierten en un mero "acto de resistencia, una prueba irrisoria de amor". Son "flores del mal", pero no en el sentido fijado por Baudelaire, sino en que se trata de seres sin voluntad y cuya presencia muestra la imposibilidad de un amor perdurable.

\section{Interlocutores}

En "Asunta" encontramos claramente a un locutor personaje, es decir, un yo poético que habla en primera persona y que, aparte de referir el poema, es también protagonista de 
los hechos: "Vengo de otra región...", “Apenas logro caminar...". Este yo poético se dirige a un interlocutor también fácilmente reconocible: Asunta.

En efecto, el locutor entabla un diálogo íntimo y permanente con ese tú, que en el texto es la amada. Este alocutario representado (pues también es personaje del poema) se mantiene desde el comienzo hasta el fin y su importancia se ve reflejada desde el propio título, que lleva su nombre. Gracias a este diálogo contante entre el yo poético y Asunta, entre el locutor y el alocutario representado, se construye una imagen original y escéptica del amor, como veremos en el siguiente apartado de nuestro análisis.

\section{Cosmovisión}

En cuanto al universo representado, lo primero que llama la atención en "Asunta" es que allí amor y muerte se confunden, adquieren una especie de alianza y se materializan en el yo, al que convierten en objeto, en un instrumento de castigo. En efecto, el yo poético se presenta a sí mismo como un ser espectral. Se trata de alguien que ha remontado fronteras muy lejanas, alguien que no es de este mundo ("Vengo de otra región, Asunta"). Este ser fantasmal ha venido para cumplir una misión: entregar flores a su interlocutor femenino, flores carentes de nombre y que son obsequiadas como "un acto de resistencia, un aprueba irrisoria de amor".

Así como la voz poética, el amor pertenece también a una región diferente. Está lejos de aquel ideal platónico que subyuga a los amantes y los lleva a realizar acciones consideradas sublimes. En estos versos el amor obliga al yo a manifestarse, lo convierte en instrumento, en un ser inconforme que debe cumplir su misión pese al deterioro de su cuerpo y a su indisposición general: "Apenas logro caminar y tengo la mueca del que no quiso volver, pero no le quedó alternativa". Como vemos, el yo ya estuvo aquí: ha vuelto de aquella frontera que cruzó alguna vez (la muerte) y ahora es el objeto que permite al amor manifestarse, terrible e ineludible a un tiempo. Asunta no puede rechazar el obsequio de la flor, de aquella "prueba irrisoria" que han entregado en sus manos. Solo le queda olerlas, captar su fragancia y encandilarse con la pasión que los pétalos transmiten.

El amor se adueña de aquello que toca; nadie que acceda a su poder conseguirá, en adelante, liberarse de aquella región lejana, pero cierta, de donde ha regresado el yo. El amor (en "Asunta" y en la mayoría de los poemas de López Degregori) es una enfermedad. Quien resulta seducido, cree por un tiempo poseer al objeto de su pasión: lo pisa, lo devora, lo humilla, actúa de la misma forma en que lo haría Asunta con las flores, de seguir los consejos de la voz poética. Pero ella no escapará, como se anticipa en uno de los últimos versos: está condenada a seguir el mismo camino que el yo transitó tiempo antes. Ese camino extraño y solitario, en su caso, no tiene punto de retorno. Las flores sin nombre, aquellos signos del idilio, perdurarán sin problemas como prueba manifiesta del poder del amor. Asunta, en cambio, no sobrevivirá. Ello explica su imposibilidad para 
responder "a los golpes densos, helados, insistentes de los vecinos", como se lee al final del poema.

\section{REFERENCIAS}

Arduini, S. (2000). Prolegómenos a una teoría general de las figuras. Universidad de Murcia.

Cebrecos, F. (1995). "Qué puede uno en el límite conceder". Una aproximación provisional a la poesía de Carlos López Degregori. Humanitas. Revista de la Facultad de Psicología, 33, 17-75.

Fernández Cozman, C. (2008). La poesía hispanoamericana y sus metáforas. Editum Signos.

Friedrich, H. (1974). Estructura de la lírica moderna. Seix Barral.

López Degregori, C. (2018). Lejos de todas partes (1978-2018). Universidad de Lima, Fondo Editorial.

O’Hara, E. (1994). Empeño en lo translúcido: la poética de C. L. D. En C. López Degregori, Lejos de todas partes (pp. 9-34). Universidad de Lima.

Urco. J. (1994). Carlos López Degregori: las grandes conmociones interiores. Lienzo, 15, 55-66.

Vega Jácome, S. (2015). Del agua a la espesura del bosque. La poesía de Carlos López Degregori. Dedo Crítico. 